Western University

Scholarship@Western

Department of Economics Research Reports

Economics Working Papers Archive

1982

\title{
The Output-Inflation Tradeoff when Prices are Costly to Change
}

Michael Parkin

Follow this and additional works at: https://ir.lib.uwo.ca/economicsresrpt

Part of the Economics Commons

Citation of this paper:

Parkin, Michael. "The Output-Inflation Tradeoff when Prices are Costly to Change." Department of Economics Research Reports, 8209. London, ON: Department of Economics, University of Western Ontario (1982). 
RESEARCH REPORT 8209

THE OUTPUT-INFLATION TRADEOFF

WHEN PRICES ARE COSTLY TO CHANGE

by

Michael Parkin*

May 1982

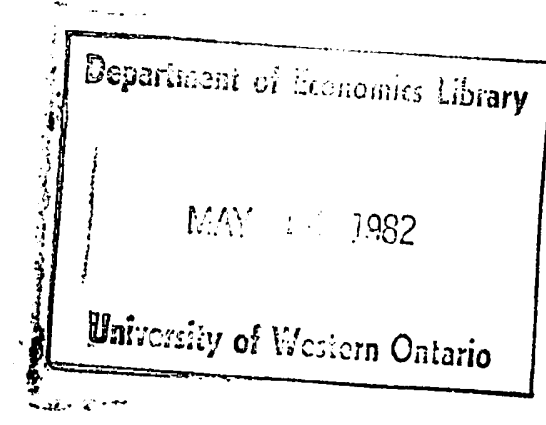

*Earlier drafts of this paper were presented at the University of Western Ontario Money Workshop, The Toronto-Queen's-Western Macro Workshop, the tenth annual conference of the Money Study Group at Brasenose College, Oxford and at seminars at Berkeley, Columbia, Queen's, New South Wales, Sydney, MacQuarrie and Queensland. I am grateful to the participants in those workshops and especially to Robin Bade, Russell Boyer; Joel Fried, Peter Howitt, Glenn MacDonald, Trien Nguyen, Jerome Stein and Randy Wigle for comments on those earlier drafts and for rescuing me from some errors. 


\section{INTRODUCTION}

It is a well established and universally accepted fact that in many economies demand variations lead to large real output and employment fluctuations and only modest movements in the inflation rate. It is also well established that the degree of responsiveness of prices and output to demand fluctuations varies over time and place. ${ }^{1}$ The dispute in macroeconomics concerns not the facts but the sources of the patterns of response of output and prices to demand fluctuations. The so-called "new classical school" maintains that the observed output-inflation tradeoff is determined by the stochastic monetary policy process that determines aggregate demand whilst the "new Keynesian school" maintains that it is rigidities (or their absence) in price and wage-setting institutions that determine the slope of the tradeoff. This paper investigates the properties of the output-inflation tradeoff in a rational expectations equilibrium economy in which costly price setting may make it inefficient for agents to vary their prices at each and every instant in response to demand fluctuations. Such an economy contrasts with one of continuous market clearing such as that analyzed in a series of celebrated papers by Robert Lucas $(1972,1973,1975)$ and by Robert Barro (1975). It should be emphasized however, that the contrast between the economy analyzed here and those of Lucas and Barro concerns the use of the market clearing assumption and not what Lucas has called the principle of equilibrium. ${ }^{2}$ The model to be developed here is an equilibrium model in the natural sense that agents could not profit from modifying their actions. Disquiet with the assumption of continuous market clearing in Lucas' work, but attraction to the rational expectations hypothesis, had led to the development of models that incorporate "Keynesian" properties arising from labor market contracts. 
The first examples of such models were those proposed by Stanley Fischer (1977) and Edmund Phelps and John Taylor (1977) and the most thoroughly worked out versions are those of John Taylor $(1979,1980)$. The key assumptions of these models which plays a role that is analogous to Keynes's assumption of a rigid money wage is that there is a fixed structure to the timing of wage changes and that individual wage changes are staggered. This produces inertia in the wage and price adjustment process so that shocks which affect current wages persist into the future and beyond the life of the longest existing contracts. The policy implication of Taylor's work is that even with rational expectations, feedback rules which to some degree accommodate price changes, can reduce the variance of real output. This policy conclusion contrasts with the famous SargentWallace (1975) proposition that, in an economy with rational expectations and continuous market clearing the variance of real output is independent of the parameters of systematic feedback rules.

The purpose of this paper is to explore the choice theoretic and equilibrium properties of Taylor's assumptions. It does so by analyzing the price and output determination process of rational maximizing agents who face a choice between two alternatives. One of these is to accept a price which is random but which ensures a zero excess demand at each and every instant. The other is to set a price for a fixed but optimally chosen period and to supply whatever quantity is demanded at that price. The literature which serves as the starting point for the analysis of price setting behavior is the work inspired by Kenneth Arrow (1959) the main contributions to which are Robert J. Barro (1972), Penelope Rowlatt (1977), Michael Mussa (1977) and Eytan Sheshinski and Yoram Weiss (1977). 
The model developed here goes well beyond those of the earlier contributions in three respects. First, agents are recognized as being free to choose between being random price takers or price setters. The circumstances in which all agents will choose one or the other of these extremes will be analyzed and the equilibrium allocation of agents between the two types will be determined. Secondly, the relative timing of price changes is analyzed to establish whether individual price changes will be uniformly distributed over time ("staggered") or concentrated together ("bunched"). Previous work has assumed that individual price changes will be uniformly staggered. Interest in the relative timing of price adjustment arises from the role played by staggering in Taylor's work. It is because of staggering that past prices affect current prices, hence, this is the key source of inertia in Taylor's analysis. Thirdly, unlike the earlier literature on price setting, explicit account is taken of the connection between the processes which generate aggregate demand and the allocation of demand to individual agents and the expectations of individual agents. The properties of the output-inflation tradeoff will be established and the effects of policy parameters on inflation and the variance of real output and prices will be examined. Specifically it will be shown that the market institutions are themselves crucially determined by the monetary policy process. An economy with low inflation and with a sizeable amount of "monetary accommodation" will be one characterized by long-term "contracts" that are staggered in the manner assumed in the new Keynesian analysis. An economy with high inflation and/or disaccommodating (negative feedback) monetary policy will be one in which "contracts" are either very short or non-existent. The market institutions and resulting slope of the outputinflation tradeoff will be shown to depend crucially upon these two aspects 
of monetary policy.

The paper proceeds in the following order. First, the model is set out (part II) and used to develop propositions concerning the optimal price determination and review process. Part III analyzes the equilibrium allocation of agents between two ways of doing business--setting prices or auctioning. The properties of the output-inflation tradeoff are also established in this section. Part IV summarizes the conclusions and suggests some extensions that seem likely to repay further investigation.

II. THE MODEL

There exists an infinite number of identical competitive producers. ${ }^{3}$ Each producer is viewed as occupying an "island" in a sense similar to that suggested by Phelps $(1970$, p . 6). The abstraction to be employed however is not identical to that suggested by Phelps. The producer is viewed as being able to sell his output in one of two ways. Either he may, by incurring a setup cost, post a price at which he is willing to sell any quantity demanded. Alternatively he may announce that a predetermined volume of output will be sold by auction. In either case, the agent must make at least one decision relating to the marketing of his output before the position of his (random) demand function is known to him. Either he must choose the price at which to sell a demand determined quantity or must choose the quantity to sell at a demand determined price.

The producer will face a downward sloping demand curve with respect to his price relative to the economy average price. It is assumed, however, that this does not present the producer with an exploitable pricequantity tradeoff. In terms of determining either the price at which to do business or the quantity to offer, the agent is required to behave as if 
he is operating in a competitive market. Any attempt to set output at a srice level which is systematically below the competitive equilibrium price will be met with a penalty so great as to ensure that no agents behave in such a manner. This penalty does not explicitly feature in the subsequent analysis. It is assumed that the penalty is so great that no one even considers deviating from competitive practises on the average. 4

In setting out the structure of the model it will be convenient to begin with a description of the demand side, then to examine how costs and prices would be determined in a hypothetical frictionless world--a world in which there are no costs of trading and therefore no problem requiring the agents either to predetermine a price or a quantity--and then go on to examine the setup in the situation visualized by the above set of abstractions.

\section{(i) Demand}

Each producer faces a demand function for its output given by:

$$
y_{i}^{d}(t)=m(t)-p(t)+\beta_{d}\left(p(t)-p_{i}(t)\right)+v_{i}(t), \beta_{d}>1
$$

where all the variables (except $t$ ) are natural logarithms and

$$
\begin{aligned}
& y=\text { real output } \\
& p=\text { price level } \\
& m=\text { money stock } \\
& v=\text { random disturbance } \\
& t=\text { time (measured continuous } 1 y) \\
& i \quad \text { indexes an individual agent, } i \in[0,1] \\
& d \quad \text { denotes demand. }
\end{aligned}
$$

The parameter $\beta_{\mathrm{d}}$ is the elasticity of demand for the producer's output with respect to relative price. 
The random disturbance to demand, $v_{i}(t)$, is assumed to be distributed in the following manner:

$$
v_{1}(t) \sim N\left(0, \sigma^{2}\right)
$$

This assumption may appear to be excessively strong. However, if a fixed term for price setting is to be derived as being optimal it is necessary that the stochastic component of demand be serially uncorrelated. Serial correlation would lead to a random price review frequency and would not generate the kind of fixed term prices emphasized in the "new Keynesian" 1iterature. 5

The relationship between the aggregates and the individual producer's outputs, prices and random shocks are defined by:

$$
z(t)=\int_{0}^{1} z_{i}(t) d i
$$

where $z=\{y, x, p, v\}$.

Notice that, aggregating (1) using (3) gives

$$
y^{d}(t)=m(t)-p(t)+v(t)
$$

which is simply the logarithmic version of the quantity equation $(M V=P Y)$. It will be immediately apparent from (14) that the assumed demand functions embody a strong restriction on the demand for goods and money, namely the absence of intertemporal substitution. In effect, "velocity", $v$, is being defined as a white noise process rather than as a variable which responds in a systematic way to changes in the expected rate of inflation. This restriction is justified in the present context on two counts. First, the purpose of the present exercise is to examine (stochastic) steady-states rather than transitions from one steady-state to another. It is, of course, only in the transition that systematic movements in velocity play a visible 
role. Secondly, it is sought to remain as close as possible to the specifications used in the "new Keynesian" literature so as to facilitate direct comparison between the results generated here and those of the previous studies. Equation (4) is precisely the form of aggregate demand function used by Taylor and since the current debate in macroeconomics concerns aggregate supply, not aggregate demand, adopting the same formulation of the latter avoids introducing extraneous differences of specification which could cloud the desired comparisons. The variable $m$, which denotes the money stock, could be viewed in a more eclectic light to be the nonstochastic component of nominal aggregate demand. However, and again so as to stay as close as possible to Taylor, I shall find it more convenient to proceed on the narrower proposition that $m$ is, indeed, the nominal money supply. The money supply is assumed to be determined by the following process:

$$
m(t)=b_{\mu} t+(1-b) p(t)
$$

$$
\begin{aligned}
\text { where } \mu= & \text { deterministic trend growth rate of money supply in the } \\
& \text { absence of accommodation } \\
1-b= & \text { degree of accommodation of price level movements. }
\end{aligned}
$$

The money supply process is specified as in (5) so as to make it possible to analyze the effects of different trend rates of money growth and different degrees of monetary accommodation on the variance of output and inflation. Thus, if $b$ is set equal to unity, then (5) becomes a fixed money supply growth rule and, if $b$ is set equal to zero, the money supply completely accommodates price level movements. 6 
(ii) Costs and Prices in a Frictionless World

The producer faces a technology which gives rise to a minimized marginal cost function,

$$
c_{1}(t)=p(t)+\frac{1}{\beta_{s}} y_{i}(t), \beta_{s}>0
$$

where $c=$ marginal cost and $\beta_{s}$ has the natural interpretation of the elasticity of supply.

In the absence of any costs of adjustment of prices or output and with competitive conditions preventing the exploitation of monopoly power,

$$
p_{i}(t)=c_{i}(t)
$$

will obtain. Using this in (4) and defining

$$
x_{i}(t) \equiv y_{i}^{d}(t)-y_{i}(t)
$$

as the excess demand for output gives:

$$
x_{i}(t)=m(t)-p(t)+\beta\left(p(t)-p_{i}(t)\right)+v_{i}(t)
$$

where $\beta \equiv \beta_{d}+\beta_{s}$.

In specifying equations (6), (7) and (8) which determine excess demand, I am implicitly defining (by choice of units) the logarithm of output when $p_{i}(t)$ equals $p(t)$ as being equal to zero. In effect this means that $I$ am abstracting from trends in the level of economic activity and am going to be concerned purely with fluctuations of the level of real output relative to its trend.

In a frictionless world in which prices and outputs may be adjusted instantly at zero cost, the competitive equilibrium price and output levels for each producer would be given by: 


$$
\begin{aligned}
& y_{i}(t)=\frac{\beta_{s}}{\beta}\left(v_{i}(t)-v(t)\right) \\
& p_{i}(t)=\mu t+\frac{(\beta-b)}{\beta b} v(t)+\frac{1}{\beta} v_{i}(t),
\end{aligned}
$$

and the aggregate levels of output and prices would be:

$$
y(t)=0
$$

and

$$
P(t)=\mu t+\frac{1}{b} v(t)
$$

Thus, the frictionless economy depicted here is a very familiar one. Output is always at its natural level and prices, which are proportional to the money stock, take all the random demand shocks. There is, of course, no role for output stabilization policies in this economy since no output fluctuations occur. There is a role for price level stabilization policies and, clearly, setting the accomodation parameter $b$ equal to infinity--an infinite degree of disaccommodation would entirely remove the noise from the price level.

The economy to be analyzed here differs from the above 'ideal' economy in a manner which does give rise to the possibility of real fluctuations occurring. It is assumed that producers are not able to achieve instantaneous and costless price and output adjustments. In fact, extremely strong assumptions are made concerning the limitations placed upon them. A producer may either

(a) Choose an output rate at each instant before the price at which that output will be sold is known and then sell the predetermined output at the (random) price that clears the market (his market) at that instant

or (b) Choose a price at which, whatever (random) demand is forthcoming, will be satisfied at that price. 
Agents who attempt to do other than (a) or (b) will fail completely and be eliminated. Specifically, failure to satisfy demand at the set price or attempts to influence the auction price by withholding output from sale will result in elimination of the agent.

\section{(iii) Price Setting and Price Taking}

A consequence of the strong assumptions stated above is that each agent must choose whether to be a price setter or a price taker. A price setter pays a fixed setup cost $\delta$ to advertise and make credible a commitment to hold a fixed price over a preannounced but optimally chosen interval $h$, and supply whatever is demanded at the set price. The expected loss arising from price setting, relative to a frictionless (ideal reference) economy, viewed from some date $T$, is assumed to be

$$
L_{s}=\int_{T}^{T+h} E\left[\left(x_{i}(t)\right)^{2} \mid I_{i}(T)\right] d t+\frac{\delta}{h}
$$

where $I_{i}(T)$ denotes the set of information $I$, available to producer $i$, at date T. This information set contains a11 past aggregates and the individual producer's own past values of output, prices, money and velocity together with knowledge of the demand and cost functions as well as the money supply process and the stochastic properties of $v_{i}$. The loss function (14) is of the same form as that used by Mussa (1977) and, aside from the fact that it is quadratic in the logarithm of $x$, is comparable to the form explicitly derived by Barro (1972) when the agent's demand function is linear and cost function is quadratic. ${ }^{7}$ Notice that the loss is expressed as a rate per unit of time and is equivalent to a present value in the absence of discounting.

A price taker produces a quantity such that the expectation of $x_{i}(t)$ is zero and accepts the random price which ensures that the quantity supplied 
is sold. The price taker does not have the option of observing and responding to the current actual price. He must make his output decision and deliver the goods to market before the price is determined. It is assumed, without explicit derivation, that a random price must, on the average, be lower than a set (fixed) price in order to attract any customers. This has been derived as an implication of equilibrium risk sharing in a very closely related setting by Costas Azariades (1975) and Martin Bailey (1974). 8 These considerations will generate an expected loss (relative to a frictionless world) for price takers which is assumed to be:

$$
\mathrm{L}_{\mathrm{a}}=\gamma \sigma_{\mathrm{p}_{\mathrm{a}}}^{2}, \gamma>0
$$

where $\sigma_{\mathrm{p}_{\mathrm{a}}}^{2}$ is the variance of an auction price.

The parameter $\gamma$ may be regarded as measuring the degree of risk aversion on the part of consumer-searchers. A value of $\gamma$ equal to 0 would imply risk neutrality and increasing values of $\gamma$ would imply increasing degrees of risk aversion. The price at which a price taker's output is sold will be determined by auction and will be that at which $x_{i}(t)=y_{i}(t)=0$, that is,

$$
p_{i}(t)=\frac{1}{\beta}\left(b \mu t+(\beta-b) p(t)+v_{i}(t)\right)
$$

From the perspective of this paper, an agent that chooses to be a price taker has no further interesting economic decisions to make. A price setter however must select the price to set and the frequency with which to revise it. These matters are now taken up.

\section{(iv) The Price Setter's Problem}

The price setter's problem is to choose $P_{i}(T)$ and an interval $h$, to minimize $\mathrm{L}_{s}$ in (14). This problem may be broken into two stages, 
namely; 1) choose the optimal price $p_{1}(T)$ for a given $h$ and 2$)$ with $p_{1}(T)$ optimally chosen, choose the optimal h.

Substituting $(9)$ in $(14)$ for $x_{i}(t)$, differentiating with respect to $p_{i}(t)=p_{i}(T)$ for all $t \in[T, T+h]$, and setting the result equal to zero gives the value of $p_{i}(T)$ which, for a given $h$, minimizes $L_{s}$ as:

$$
p_{i}(T)=\frac{1}{\beta h} \int_{T}^{T+h}\left\{b \mu t+(\beta-b) E\left(p(t) \mid I_{i}(T)\right)+E\left(v_{i}(t) \mid I_{i}(T)\right)\right\} d t
$$

Inspection of (17) reveals that $p_{i}(T)$ is the price which is expected to deliver $x_{i}=0$ at $t=T+h / 2$. Given the stochastic assumption (2), it is clear that

$$
E\left(v_{i}(t) \mid I_{i}(T)\right)=0 \text { for } t=T, \ldots, T+h
$$

This is a crucial step in the analysis. It follows from the assumption of non-autocorrelated random disturbances. Any disturbance which has just been observed $(\mathrm{T}-\mathrm{dT})$ is of no assistance in forecasting future values of the random disturbances of $v_{i}(t)$. Furthermore, if such information was of assistance in forecasting future values of random disturbance, it would not be efficient to be contemplating setting a price for a fixed future interval. Given this, the choice of $p_{i}(T)$ becomes

$$
p_{i}(T)=\frac{1}{\beta h} \int_{T}^{T+h}\left\{b \mu t+(\beta-b) E\left(p(t) \mid I_{i}(T)\right)\right\} d t
$$

Thus, the price that will be set by an individual agent at time $T$ depends only on two things; the trend value of the money supply and the path of average prices that the agent expects will prevail over the interval from $T$ to $T$ th. The noise term $v_{i}(t)$ does not influence set prices.

The choice of $h$ requires the explicit evaluation of equation (19), which is only possible after more detailed conditions are imposed on price 
determination. Two extreme alternative assumptions will be explored. The first will be called "bunching" and is the case in which all prices are set on the same date by all agents and subsequently reviewed on the same date $(T+h)$. The second alternative called "staggering" is one in which an equal fraction of all agents review their prices at each instant so that the average price level changes continuously, although each individual agent conducts a price review only once every $h$. Further, the possibility that some prices are determined at each instant by auctions must also be allowed for in calculating the average price level and its rational expectation. This possibility is dealt with next.

(a) The Average Price Leve1

Define the fraction of agents taking auction prices as $\lambda$. Then the average price level will be

$$
p(t)=\int_{0}^{\lambda} p_{i}^{a}(t) d i+\int_{\lambda}^{1} p_{i}^{s}(t) d i
$$

where $\mathrm{p}^{\mathrm{a}}$ denotes an auction price

$\mathrm{p}^{\mathrm{s}}$ denotes a set price.

Since an individual auction price is given by (16), the contribution of auction prices to the average price level, may be calculated as:

$$
\int_{0}^{\lambda} p_{i}^{a}(t) d i=\int_{0}^{\lambda}\left[\frac{1}{\beta}\left(b \mu t+(\beta-b) p(t)+v_{i}(t)\right)\right] d i
$$

and, using this in (20) and evaluating the integral gives:

$$
p(t)=\frac{1}{\lambda b+(1-\lambda) \beta}\left\{\lambda b \mu t+\beta \int_{\lambda}^{1} p_{i}^{s}(t) d i+\int_{0}^{\lambda} v_{i}(t) d i\right\}
$$

Notice that (22) states that, with no auctions, $(\lambda=0)$, the price level $\mathrm{p}(\mathrm{t})$ is equal to the average of all the prices which have been set, $\int_{0}^{1} p_{i}^{s}(t) d i$, and 
that with all agents acting as price takers, $(\lambda=1)$, the price level is $\mu t+\frac{1}{b} v(t)$, the same value as would occur in the frictionless world depicted in (ii) above. When $0<\lambda<1$, the price level is a weighted. average of these two extremes with weights $\lambda b /(\lambda b+(1-\lambda) \beta)$ and $(1-\lambda) \beta /$ $(\lambda b+(1-\lambda) \beta)$ on auction and set prices respectively.

It is now possible to turn to the next stage of the price setter's problem. First the "bunching" case is considered.

\section{(b) Bunching}

Under the assumption that all price changes are "bunched" on the same date, it is clear that each price setting agent will have a price given by:

$$
p_{i}^{s}(t)=p_{i}^{s}(T), t=T, \ldots, T+h
$$

Using this in (22) gives:

$$
p(t)=\frac{1}{\lambda b+(1-\lambda) \beta}\left\{\lambda b \mu t+\beta \int_{\lambda}^{1} p_{i}^{s}(T) d i+\int_{0}^{\lambda} v_{i}(t) d i\right\}
$$

Take the expectation of $(24)$, conditional on $I_{i}(T)$ to give:

$$
\begin{aligned}
E\left(p(t) \mid I_{i}(T)\right)=\frac{1}{\lambda b+(1-\lambda) \beta}\{\lambda b \mu t+\beta & \int_{\lambda}^{1} E\left(p_{j}^{s}(T) \mid I_{i}(T)\right) d_{j}+ \\
& \left.\int_{0}^{\lambda} E\left(v_{j}(t) \mid I_{i}(T)\right) d j\right\}, t=T, \ldots, T+h
\end{aligned}
$$

Notice that producer I's expectation of the price level depends on $i$ 's expectation of the prices currently being set by a11 the other price setters as well as on expectations of the shocks hitting the price takers. This latter expectation is clearly zero and so is easily disposed of. Some care is needed, however, in dealing with the expectations of the prices being set by others for those prices are in turn being set on the basis of their 
expectations of everyone else's prices. To make further progress with this, use (25) (with the last term involving $v_{i}$ set equal to zero) in (19) and evaluate the integral in $t$ to determine the price to be set by agent j as :

$$
p_{j}(T)=\frac{b_{\mu}}{\lambda b+(1-\lambda) \beta}\left(T+\frac{h}{2}\right)+\frac{(\beta-b)}{\lambda b+(1-\lambda) \beta} \int_{\lambda}^{1} E\left(p_{k}^{s}(T) \mid I_{j}(T)\right) d k
$$

Now calculate i's expectation of (26) as:

$$
\begin{aligned}
E\left(p_{j}(T) \mid I_{i}(T)\right)= & \frac{b_{\mu}}{\lambda b+(1-\lambda) \beta}\left(T+\frac{h}{2}\right) \\
& +\frac{(\beta-b)}{\lambda b+(1-\lambda) \beta} \int_{\lambda}^{1} E\left(E\left(p_{k}^{s}(T) \mid I_{j}(T)\right) \mid I_{i}(T)\right) d k
\end{aligned}
$$

so that i's price will be set using (27) in i's equivalent of (26) as

$$
\begin{aligned}
p_{i}(T)= & \frac{b \mu}{\lambda b+(1-\lambda) \beta}\left(T+\frac{h}{2}\right)+\frac{(\beta-b) b_{\mu}(T+h / 2)}{[\lambda b+(1-\lambda) \beta]^{2}} \\
& +\frac{(\beta-b)^{2}}{[\lambda b+(1-\lambda) \beta]^{2}} \int_{\lambda}^{1} \int_{\lambda}^{1} E\left(E\left(p_{k}^{s}(T) \mid I_{j}(T)\right) \mid I_{i}(T)\right) d k d j
\end{aligned}
$$

It appears as if we are about to embark upon an infinite regress such as that which arises in the models proposed by Roman Frydman (1981) and Edmund Phelps (1981), some resolutions of which have been proposed by Robert Townsend $(1980,1981)$. A moment's reflection reveals however, that that is not so. There is sufficient structure in this model to avoid that problem and in a way that does not involve resorting to any of the devices proposed by Townsend. We know (and every producer knows) that, at date $T$, a11 price setters face an identical problemand an identical set of relevant information. It is true that each agent knows only his own $v_{i}(T)$ but, because of the nature of the $v_{i}$ process that knowledge is not used by any agent in the price setting decision and all agents know that fact. That being so, everyone knows that everyone will select the same price at $T$, i.e., 


$$
P_{i}(T)=p_{j}(T) \text { for all } i \text { and } j
$$

from which it follows immediately that each agent $i$ will expect each other agent $j$ to be setting the same price as $i$ is setting. This immediately implies that:

$$
p_{i}(T)=\frac{b_{\mu}}{\lambda b+(1-\lambda) \beta}(T+h / 2)+\frac{(1-\lambda)(\beta-b)}{\lambda b+(1-\lambda) \beta} p_{i}(T)
$$

or, more simply,

$$
p_{i}(T)=\mu(T+h / 2)
$$

Thus, all price setting agents will select the same price as each other and further will set a price which, at the mid-point of the interval $\{\mathrm{T}, \mathrm{T}+\mathrm{h}\}$ is expected to give zero excess demand. Using (31) in (22) gives the average price level under bunching, denoted by $p_{b}(t)$, as:

$$
P_{b}(t)=\frac{1}{\lambda b+(1-\lambda) \beta}\left\{\lambda b \mu t+(1-\lambda) \beta_{\mu}\left(T+\frac{h}{2}\right)+\int_{0}^{\lambda} v_{i}(t) d i\right\}
$$

This states that the average price level is made up of three components: a trend which grows at rate $\mu$, weighted by $\underline{a} \equiv \lambda b /(\lambda b+(1-\lambda) \beta)$; a "step" at each interval $T, T$ th,... of size $h \mu$ weighted by $(1-\underline{a})$; and noise injected via auction prices.

\section{(c) Uniform Staggering}

Under uniform staggering of price changes, each price setting producer will change his price at intervals of length $h$, but at each instant, a uniform fraction, $1 / \mathrm{h}$, of all price setters will be setting a new price. Since only fraction $(1-\lambda)$ of agents are price setters this means that at each instant, fraction $(1-\lambda) / h$ of all producers will be setting a new price to prevail for the interval from $t$ to $t$ th. The prices which are set at a particular date $t$, which will be denoted as $q(t)$ will be the same 
for all agents by virtue of the stochastic assumption (2) and the discussion in the preceding section. At any one instant, prices which have been set in the past all the way back to $t-h$, will still prevail. In the light of these considerations, the contribution of set prices to the average price level may be expressed as:

$$
\int_{\lambda}^{1} p_{i}^{s}(t) d i=\frac{(1-\lambda)}{h} \int_{t-h}^{t} q(T) d T
$$

Using this in (22) gives:

$$
p(t)=\frac{1}{\lambda b+(1-\lambda) \beta}\left\{\lambda b_{\mu} t+\frac{(1-\lambda)}{h} \beta \int_{t-h}^{t} q(T) d T+\int_{0}^{\lambda} v_{i}(t) d i\right\}
$$

But, $q(T)$ is given by (19) so that, using this in (34) gives

$$
\begin{aligned}
p(t)=\frac{1}{\lambda b+(1-\lambda) \beta}\left\{b_{\mu t}\right. & +\frac{(1-\lambda)(\beta-h)}{h^{2}} \int_{t-h}^{t} \int_{T}^{T+h} E(p(t) \mid I(T)) d t d T \\
& \left.+\int_{0}^{\lambda} v_{i}(t) d i\right\}
\end{aligned}
$$

Notice that the term but is no longer scaled by $\lambda$ as it was in the "bunching" case, but is independent of the fraction of agents who auction. This arises because some set prices are being changed at each instant and so the average of set prices, 1ike the average of auction prices rises by b $\mu$ at each $t$ (ceteris paribus).

It is interesting to note the way in which price level expectations affect current prices. The expected price level enters equation with a triangular distribution between $t-h$ and $t$ th, the weight being greatest at $t$. The reason for this is that some prices which still prevail at $t$ were set at $t-h$ for the period from $t-h$ to $t$ and prices being set at $t$ will prevail until $t$ th. The expected price level over the interval $\{t-h, t\}$ was thus a relevant input into the calculations made at $t-h$ and the expected price level over the interval $\{t, t+h\}$ is a relevant input into the calculations made at $t$. Consider 
an agent who is setting a price a little later than $t-h$ : such an agent will have to form an expectation of the price level that runs forward beyond the current period $t$. The same will be true for agents setting prices at all dates between $t-h$ and $t$. The current period, $t$, will always feature as one of the period's prices the expectation of which is relevant for a price being set at any date over the interval from $t$ back to $t-h$. However, as we (conceptually) move through that interval from $t-h$ to $t$, so prices that did prevail in the past cease to be relevant to the current price setting decision and prices that will prevail in the further future become relevant. As we chop off dates after $t-h$ but before $t$, so we add dates after $t$ and approaching $t$. It is evident that, since the current period $t$ features in all the decisions to be taken between $t-h$ and $t$ so the weight which appears on that period's price level will be greatest. The weight that appears on the price level at $t-h$ like that on the price level at $t$ th will be arbitrarily close to zero since those periods feature only in the price decisions that were taken at $t-h$ and those being taken at $t$. All the price decisions taken strictly inside the interval $t-h$ to $t$ will have ignored the price level at $t-h$ and that at $t$ th. The weights rise from $t-h$ and decline to $t$ th in a linear fashion. Equation (35) is in many respects similar to what John Taylor calls the "reduced form contract equation". 9 The key differences between equation (35) and Taylor's "reduced form contract equation" are first that the possibility that some prices are determined by auctions are included in equation (35) whilst in Taylor's formulation all prices (wages in his model) are set, and secondly, the only noise that enters equation (35) is that on the auction prices. Noise affecting demand facing those who choose to set prices does not find its way into the price setting behavior of agents. 
To solve for the actual value of the price level under uniform staggering together with the prices that will be set by the individual agents it is necessary to proceed in a slightly less direct manner than was possible under bunching. Notice from an inspection of equation (35) that, under uniform staggering, the actual price level depends upon three things: first, time $(t)$, second, the aggregate noise influencing the demand functions of those agents who allow their prices to be determined by auction and third, the expectations of the price level formed at $T$ for $t, t$ running through from $T$ to $T$ th but as formed at each date $T$ over the interval $t-h$ to $t$. Since those expectations of prices that enter equation (35) are always future expectations they can only depend upon those things that determine actual prices which, evidently are only time and the aggregate noise hitting the auctioning agents. The solution for prices under uniform staggering, denoted $p_{u}(t)$, must therefore be of the general form

$$
p_{u}(t)=\pi_{0}+\pi_{1} t+\pi_{2} \int_{0}^{\lambda} v_{i}(t) d i
$$

where the $\pi_{i}$ are coefficients to be determined. The expectation of (36) will be the same for all agents and will be

$$
E\left(P_{u}(t) \mid I(T)\right)=\pi_{0}+\pi_{1} t
$$

Using equation (37) in (35) solving the resulting equation by evaluating the integral and then equating the result term by term with equation (36) enables the undetermined coefficients $\pi_{0}, \pi_{1}$ and $\pi_{2}$ to be evaluated as follows

$$
\left.\begin{array}{l}
\pi_{0}=0 \\
\pi_{1}=\mu \\
\pi_{2}=\frac{1}{\lambda b+(1-\lambda) \beta}
\end{array}\right\}
$$


Using these values for the undetermined coefficients of (36) gives us the solution for the price level under uniform staggering,

$$
p_{u}(t)=\mu t+\frac{1}{\lambda b+(1-\lambda) \beta} \int_{0}^{\lambda} v_{i}(t) d i .
$$

of course the individual price setter will have a price given by

$$
p_{i}^{s}(t)=\mu\left(T+\frac{h}{2}\right) \quad t=T, \ldots, T+h,
$$

which is naturally the same as under bunching.

In both cases, under bunching and uniform staggering, the price level solution may be regarded as a combination of what Hicks has called Fixprice and Flexprice. ${ }^{10}$ The set prices are fixed in the sense that no noise gets into the price determination process. Set prices are fixed, however, not absolutely but relative to the noise that is being generated. The auction prices are Hicks's Flexprices. Thus, these price equations combine the price fixity of Keynesian theory with the price flexibility of classical theory.

(v) The Choice of $h$

The problem of choosing $h$ may now be solved. Under bunching, by using the solution (equation (32)) for the price level and the expectation of (31) for the expected price level, equation (14) may be evaluated completely for the expected loss that would be incurred by a firm setting prices in an economy in which all other set prices were bunched and fraction $\lambda$ of agents were price takers. In that case, the loss denoted $L_{b}$ (loss under bunching) would be:

$$
I_{b}=\frac{1}{12}\left(\frac{b \beta \mu h}{\lambda b+(1-\lambda) \beta}\right)^{2}+\left(1+\frac{\lambda(\beta-b)^{2}}{(\lambda b+(1-\lambda) \beta)^{2}}\right) \sigma^{2}+\frac{\delta}{h}
$$

The three components of the loss are readily interpreted. The middle 
component is simply the irreducible loss that arises from the fact that there is demand noise in the economy. That is, demand facing an individual agent is fluctuating in a random and uncontrollable fashion. The first term states that the loss will increase proportionately with the square of the length of time over which prices are set. This reflects the idea that as time proceeds, with the money supply continuously growing at rate $\mu$ the price level set at time $T$ will become increasingly inappropriate. Thus, the longer the price is held fixed the bigger the loss that will be incurred, other things equal. The final term reflects the fact that the setup $\cos t, \delta$, has to be incurred each time the price is changed and, therefore, the rate of loss per unit of time decreases as $h$ increases, since the setup cost is spread over a longer period of time.

Using the solution for prices under uniform staggering, equation (39) and its expectation in equation (14), gives the loss under uniform staggering, denoted $\mathrm{L}_{\mathrm{u}}$, as

$$
L_{u}=\frac{1}{12}(\beta \mu h)^{2}+\left(1+\frac{(\beta-b)^{2}}{(\lambda b+(1-\lambda) \beta)^{2}}\right) \sigma^{2}+\frac{\delta}{h}
$$

The remarks above concerning the three terms in equation (41) apply also to the three terms in equation (42). The first term in each of those two equations differs only in that in (41) the term $b \beta /(\lambda b+(1-\lambda) \beta)$ appears, where in (42) $\beta$ appears. The reason for this is quite natural and is most readily seen if we consider the special case of $\lambda=0$, i.e., all are price setters. In that case, the term $b \beta / \lambda b+(1-\lambda) \beta$ simply becomes $b$. What this loss then reflects is the fact that, under bunching, relative prices never get out of line with each other, although the absolute price level is never (except for once each $h$, that is at $T+h / 2$ ) at the zero excess demand 
level. Therefore, under bunching, it is the effects of a "wrong" absolute price level relative to the money supply which generates the loss from holding a fixed price. From equation (5) it is clear that the absolute price levelmoney stock discrepancy gets a weight of b. In contrast to this, under staggering, the absolute price level is always correct in relation to the money supply since both increase at the same rate. What is "wrong" in the staggering case is the individual agent's price relative to the average price since the average price level is rising continuously but an individual agent's prices are fixed. The parameter $\beta$ is what reflects the strength of the relative price term on an individual agent's excess demand and it is that parameter, therefore, which appears in equation (42).

The solution for optimal $h$ under bunching $\left(h_{b}^{*}\right)$ and uniform staggering $(\mathrm{h} *)$ are

and

$$
h_{b}^{*}=\left[\frac{6 \delta(\lambda b+(1-\lambda) \beta)^{2}}{(\beta b \mu)^{2}}\right]^{1 / 3}
$$

$$
h *=\left(\frac{6 \delta}{\beta^{2} \mu^{2}}\right)^{1 / 3}
$$

respectively.

These solutions are directly comparable with those obtained by Musa (1977) and Sheshenski and Weiss (1977). Since the solutions are almost identical, differing only in whether or not the term $(\lambda b+(1-\lambda) \beta) / \beta b$ or $\beta$ appears, they may be discussed together. Naturally enough, the higher is the cost of price setting, $\delta$, the longer is the period for which the price is set (with an elasticity of $1 / 3$ ). The higher is the money supply growth rate, the shorter is the period for which the price is set (with an elasticity of $-2 / 3$ ). This last result implies, of course, that the step change in the price level will increase as the money supply growth rate 
increases and with an elasticity of 1/3. A11 these propositions are in agreement with those in the existing literature cited. Some additional propositions are contained in equations (43) and (44) not to be found in the existing literature. First, under bunching, the fraction of agents auctioning their output will affect the optimal review interval for price setting. In this case, $\beta$ will be greater than $b$ (as demonstrated below) and, the bigger is the fraction of agents that auction, the shorter will be the optimal review interval for the price setters. In the case of uniform staggering of price setting, the optimal price review interval is independent of the fraction of agents auctioning. The reason for these different results is that under bunching, each agent who sets a price will have the "correct" price in relation to the other price setters but will have a price that is "wrong" with respect to the auction prices except for once (half way through) the price review period. Under uniform staggering, each price setter has a price which is "wrong" with respect to all other agents regardless whether those other agents set prices or auction except for the midway point between price reviews. Second, the degree of monetary accommodation influences the optimum review interval under bunching (provided not all agents auction). In that case, the larger is the value of the parameter $b$ (the less the degree of accommodation or equivalently the greater the degree of negative feedback to prices) the shorter will be the optimum price review.

The minimized losses under the two alternative regimes are obtained by using equations (43) and (44) to eliminate $h$ in equations (41) and (42). These minimized losses under the two regimes are:

$$
L_{b}^{*}=\left(\frac{9}{16}\right)^{1 / 3}\left(\frac{\delta b \beta \mu}{\lambda b+(1-\lambda) \beta}\right)^{2 / 3}+\left(1+\frac{\lambda(\beta-b)^{2}}{\left(\lambda b+(1-\lambda \beta)^{2}\right.}\right) \sigma^{2}
$$

and 


$$
\mathrm{L}_{\mathrm{u}}^{*}=\left(\frac{9}{16}\right)^{1 / 3}(\delta \beta \mu)^{2 / 3}+\left(1+\frac{\lambda(\beta-b)^{2}}{(\lambda b+(1-\lambda) \beta)^{2}}\right) \sigma^{2}
$$

Will agents attempt to bunch or to stagger? It is assumed that agents will attempt to minimize their losses from their price setting activity. If they evaluate the loss from bunching as being less than that from uniformly staggering they will attempt to bunch. If they see the losses from uniform staggering as being less than those from bunching they will attempt to uniformly stagger their price adjustments. It is necessary to be clear however, that whether price adjustments will be bunched or uniformly staggered is not something which a single agent can decide. Rather that is the outcome of a market experiment. No explicit analysis is offered of how this might come about. In what follows, it will be assumed that somehow or other the economy does manage to converge upon the loss minimizing solutions.

It is now possible to use the results generated above to examine the properties of the output-inflation tradeoff in this economy and to examine the effects of alternative settings of the policy parameters, $\mu$ and $b$, on the behavior of the economy.

III. AUCTION PRICES, SET PRICES AND THE OUTPUT-INFLATION TRADEOFF It is convenient to begin by recalling the solutions for the price level under bunching and uniform staggering. These solutions are

$$
\begin{aligned}
& P_{b}(t)=\frac{1}{\lambda b+(1-\lambda) \beta}\left\{\lambda b \mu t+(1-\lambda) \beta_{\mu}\left(T+\frac{h}{2}\right)+\int_{0}^{\lambda} v_{i}(t) d i\right\} \\
& P_{u}(t)=\mu t+\frac{1}{\lambda b+(1-\lambda) p} \int_{0}^{\lambda} v_{i}(t) d i
\end{aligned}
$$

For the purpose of examining the tradeoff between output and inflation it is useful to focus on the devlation of the price level from its expected 
level (which may be thought of as the unanticipated rate of inflation) and deviations of output from the natura! level. Defining the deviation of the price level from its expected level as

$$
\tilde{p}(t)=p(t)-E(p(t) \mid I(t))
$$

then

$$
\tilde{p}(t)=\frac{1}{\lambda b+(1-\lambda) \beta} \int_{0}^{\lambda} v_{i}(t) d i
$$

regardless of whether prices are set in a bunched or uniformly staggered manner. The solution for output is obtained by aggregating over all the Individual excess demand functions to give

$$
x(t)=b_{\mu} t-b p(t)+v(t)
$$

Using the price solution under bunching (32) in the above gives the deviation of output from its natural rate under bunching as

$$
x(t)=\frac{(1-\lambda) \beta b_{\mu}}{\lambda b+(1-\lambda) \beta}\left(t-T-\frac{h}{2}\right)+\frac{(1-\lambda)(\beta-b)}{\lambda b+(1-\lambda) \beta} \int_{0}^{\lambda} v_{i}(t) d i+\int_{\lambda}^{1} v_{i}(t) d i
$$

Using the price solution under uniform staggering (39) in equation (49) above gives

$$
\tilde{x}(t)=\frac{(1-\lambda)(\beta-b)}{\lambda b+(1-\lambda) \beta} \int_{0}^{\lambda} v_{i}(t) d i+\int_{\lambda}^{1} v_{i}(t) d i
$$

It is immediately.clear that the deviations of output from the natural rate under uniform staggering arise purely from the random disturbances which affect both the auction price takers and the price setters whilst deviations under bunching consist of those same random deviations plus a systematic component arising from the effects of bunching itse1f. It will be convenient to think of the first term in equation (50) as describing the "seasonal" fluctuations in aggregate excess demand. That is they will be seasonal in the sense that they are systematically related to the stage in the interval over which prices 
are set. At the instant prices are revised, there will be a large negative component in aggregate excess demand. At the instanc before the next price review there will be a large positive value of excess demand and at the half way point there will be a zero value. This "seasonal" variation

in aggregate excess demand will be abstracted from in discussing and interpret- 3 ing the nature of the output equation relationship. Thus, under bunching, define the nonsystematic component of deviations of output from the natural rate as

$$
\tilde{\mathbf{x}}(t)=\frac{(1-\lambda)(\beta-b)}{\lambda b+(1-\lambda) \beta} \int_{0}^{\lambda} v_{i}(t) d i+\int_{\lambda}^{1} v_{i}(t) d i
$$

This of course is identical to the deviation of output from the natural rate under uniform staggering given by equation (51).

\section{(i) The Output-Inflation Tradeoff}

The output-inflation tradeoff implied by the above model is obtainable directly from $(48)$ and $(51,52)$. Using $(48)-(51,52)$ it is apparent that

$$
\tilde{x}(t)=(1-\lambda)(\beta-b) \tilde{p}(t)+\int_{i}^{1} v_{i}(t) d i
$$

The slope of the tradeoff will be equal to the fraction of agents who set their prices (one minus the fraction who auction) multiplied by the difference between the demand elasticity $\beta$ and the coefficient of accomodation $b$. Clearly, the slope will be positive (the usual case) only if $\beta>b$ and $\lambda<1$. With $\lambda<1$ and $b>\beta$ the tradeoff would have a negative slope arising from the contemporaneous negative feedback from the price level to the money stock.

The "noise" associated with the tradeoff evidently depends on $\lambda$. With all agents setting prices, $(\lambda=0)$ the aggregate velocity shock $\left(\int_{0}^{1} v_{i}(t) d i \equiv v(t)\right)$ hits output and the slope of the tradeoff in this case is 
$(\beta-b)$. If no prices are set $(\lambda=1)$ then none of the velocity noise affects output and the tradeoff has zero slope (or, in the more commonly employed $\tilde{\mathrm{p}}, \tilde{\mathrm{x}}$ space, is vertical). These are all propositions, of course, about the "short-run" tradeoff. The long-run relationship embodies the "natural rate hypothesis" by construction.

It is now evident that both the slope and the noisiness of the outputinflation tradeoff depends on both $\beta-b$ and the fraction of agents who set prices $(1-\lambda)$ and that in order to progress further in understanding the properties of the tradeoff it is necessary to examine more closely the determination of $\lambda$.

It will be assumed that, in deciding whether to set prices or to allow prices to be auction-determined, agents will only pay attention to the comparative losses involved in the two activities. If the loss attaching to auctioning is less than that arising from price setting then agents will auction and vice versa. There will be an equilibrium allocation of agents between the two marketing techniques when the loss from price setting and the loss from auctioning are equal and when a rise in the fraction of prices set by auction would lead to a rise in the loss from auctioning greater than the rise in the loss from price setting. In order to determine the value of $\lambda$ it is necessary to examine more carefully the losses involved in auctioning and to compare those with the losses attaching to price setting under the two regimes.

\section{(ii) The Loss from Auctioning}

The loss from auctioning specified in (15) above may be calculated straightforwardly by establishing the variance of an individual auction price which is: 


$$
\sigma_{P_{a}}^{2}=\frac{1}{\beta^{2}}\left(1+\frac{\lambda(\beta-b)^{2}}{(\lambda b+(1-\lambda) \beta)^{2}}\right) \sigma^{2}
$$

Using this in equation (15) gives the loss from auctioning as

$$
L_{a}=\frac{\gamma}{\beta^{2}}\left(1+\frac{\lambda(\beta-b)^{2}}{(\lambda b+(1-\lambda) \beta)^{2}}\right) \sigma^{2}
$$

The task now is to compare the loss under auctioning given in equation (55) with the losses that would arise under price setting either under the bunching or unfform staggering case. To facilitate this comparison define

$$
\begin{aligned}
& L_{a}=L_{a}(\lambda) \\
& L_{s}^{*}=L_{s}^{*}(\lambda)
\end{aligned}
$$

The values which $\lambda$ may take on, either 0 or 1 , or some interior value will be determined by the following inequalities:

$$
\begin{aligned}
& \lambda=0 \text { if } L_{a}(0) \geq L_{s}^{*}(0) \\
& \lambda=\lambda^{*} \text { if } L_{a}(0)<L_{s}^{*}(0), \\
& \text { and } L_{a}(1)>L_{s}^{*}(1) \\
& \lambda=1 \text { if } L_{a}(1) \leq L_{s}^{*}(1)
\end{aligned}
$$

For the case where set prices are bunched, that is where $\beta>b$, the inequalities (57) are:

$$
\begin{aligned}
& \lambda=0 \text { if } \quad\left(\frac{\gamma}{\beta^{2}}-1\right) \sigma^{2} \geq\left(\frac{9}{16}\right)^{1 / 3}\left(\delta b_{\mu}\right)^{2 / 3} \\
& \left.\begin{array}{l}
\lambda=\lambda^{*} \text { if } \quad\left(\frac{\gamma}{\beta^{2}}-1\right)\left(\frac{\beta}{b}\right)^{2 / 3} \sigma^{2}<\left(\frac{9}{16}\right)^{1 / 3}(\delta \beta \mu)^{2 / 3}<\left(\frac{\gamma}{\beta^{2}}-1\right)\left(1+\frac{(\beta-b)^{2}}{b^{2}}\right) \sigma^{2} \\
\lambda=1 \quad \text { if } \quad\left(\frac{\gamma}{\beta^{2}}-1\right)\left(1+\frac{(\beta-b)^{2}}{b^{2}}\right) \sigma^{2} \leq\left(\frac{9}{16}\right)^{1 / 3}(\delta \beta \mu)^{2 / 3}
\end{array}\right\}=
\end{aligned}
$$


Under uniform staggering, with $b>\beta$, the values of $\lambda$ will be given

by

$$
\begin{aligned}
& \begin{array}{l}
\lambda=0 \text { if }\left(\frac{\gamma}{\beta^{2}}-1\right) \sigma^{2}>\left(\frac{9}{16}\right)^{1 / 3}(\delta \beta \mu)^{2 / 3} \\
\lambda=\lambda * \text { if }\left(\frac{\gamma}{\beta^{2}}-1\right) \sigma^{2}<\left(\frac{9}{16}\right)^{1 / 3}(\delta \beta \mu)^{2 / 3}<\left(\frac{\gamma}{\left.\beta^{2}-1\right)\left(1+\frac{(\beta-b)^{2}}{b^{2}}\right) \sigma^{2}}\right.
\end{array} \\
& \lambda=1 \text { if }\left(\frac{\gamma}{\beta^{2}}-1\right)\left(1+\frac{(\beta-b)^{2}}{b^{2}}\right) \sigma^{2}<\left(\frac{9}{16}\right)^{1 / 3}\left(\delta \beta_{\mu}\right)^{2 / 3}
\end{aligned}
$$

Inspection of conditions (58) and (59) reveals immediately that if $\gamma<\beta^{2}$ no prices will be set. The loss from auctioning will be less than the loss from price setting (whether bunched or staggered) for all values of $\lambda$ between zero and one and so there will be no incentive to set prices. A necessary condition, therefore, though not sufficient, for some prices to be set is $\gamma>\beta^{2}$. Given the "story" used here, this means that there must be sufficient risk aversion relative to excess demand elasticity. 11

For the following discussion, it will be assumed that $\gamma>\beta^{2}$. If that is the case and if $\lambda$ takes on an interior value, its particular value will be determined by the six parameters in the model in the following way:

$$
\begin{gathered}
\lambda^{*}=\lambda\left(\gamma, \delta, \beta, b, \mu, \sigma^{2}\right) \\
-,+,+,+,+,-
\end{gathered}
$$

where the signs $(+,-)$ indicate the sign of the partial derivative ${ }^{12}$ of $\lambda$ with respect to the argument in question for interior values of $\lambda$. For small enough values of $\gamma$ or $\sigma^{2}$ or large enough values of $\delta, \beta, b$ and $\mu$, there will be no prices set; all agents will accept an auction price. At the other extreme, for high enough values of $\gamma$ and $\sigma^{2}$ and low enough values of the other four parameters no one will auction and all prices will be set. In the intermediate range, the fraction that auctions will be influenced in 
the directions indicated by the signs of the partial derivatives of equation (60). A rise in the value of $\gamma$ obviously raises the loss from auctioning leaving the loss from price setting unchanged and therefore other things equal would make auctioning less attractive and therefore lower the fraction that auctions. By analogous reasoning, a rise in the parameter $\delta$ raises the setup cost of price adjustment and therefore raises the loss from price setting while leaving the loss from auctioning unchanged. A rise in $\delta$ would therefore make auctioning more attractive at the margin and raise the fraction that auction. The effect of $\beta$ is more complex It will lower the loss arising from auctioning and raise the loss arising from price setting. The parameter b plays a similar role. It lowers the loss from auctioning and lowers the loss from price setting but by less than the reduction in the loss from auctioning. Both of these therefore would have the same direction of effect on the fraction of agents who auction. A rise in the trend money supply growth rate $\mu$ would raise the loss from price setting whilst leaving that from auctioning unchanged and therefore would raise the fraction that auction. Finally, a rise in the variance of the demand shock raises the loss from both auctioning and price setting but raises the loss more under auctioning in the interior solution case.

It is now possible to return to an examination of the determinants of the slope of the output-inflation tradeoff and to examine the influences of policy parameters on that slope. Recall that the slope of the tradeoff is given by $(1-\lambda)(\beta-b)$. It is now possible to examine how $\lambda$ will be influenced by variations both in $b$, the degree of monetary accommodation and $\mu$, the trend growth rate of the money supply. First consider the effects of $b$. 
If $b=0$, this implies complete accommodation of price level movements. In such a case, if any prices were set, they would be set under bunching since $\beta$ would be greater than $b$. With $0<b<1$ there is partial accommodation of price level movements. Again if any prices were set they would be set by bunching since $\beta$ necessarily must be greater than 1 (a condition for positive marginal revenues). With $b>1$ but still less than $\beta$ there would be some tendency for monetary policy to lean against the wind of price changes--that is for there to be some instantaneous negative feedback. St111, in this case if any prices were set they would be set in a bunched manner. At $b=\beta$ the losses arising from both auctioning and price setting would be neutral with respect to the fraction of agents that auction and either all prices or no prices would be determined by auction. If the prices were set, whether they were bunched or staggered would be a matter of indifference. With $b>\beta$, there would be stronger negative feedback and, if any prices were set in this range they would be uniformly staggered. How do variations in $b$ over this range influence the slope of the outputinflation tradeoff?

In the perfect accommodation case, $b \rightarrow 0$, then the losses under price setting (bunching) and auctioning would be

$$
\left.\begin{array}{l}
L_{b}^{*}=\left(1+\frac{\lambda}{(1-\lambda)^{2}}\right) \sigma^{2} \\
L_{a}=\frac{\gamma}{\beta^{2}}\left(1+\frac{\lambda}{(1-\lambda)^{2}}\right) \sigma^{2}
\end{array}\right\}
$$

Clearly, if $\gamma<\beta^{2}$ all prices will be determined by auction and if $\gamma>\beta^{2}$ all prices will be set. There are no intermediate solutions under complete accommodation. In the case that $\gamma>\beta^{2}$ and therefore of all prices being set, the slope of the tradeoff will simply be $\beta$. In the case of $\gamma<\beta^{2}$ the tradeoff 
will have zero slope.

Next consider values of $0<b<\beta$. These are values which involve partial accommodation $(b<1)$ or some degree of negative feedback or leaning into the wine $(1<b<\beta)$. For some low values of $b$, provided that $\gamma>\beta^{2}$, there will be no auctions--all prices will be set. As higher and higher values of $b$ are contemplated so eventually the condition for zero auctions will be violated (see inequalities (58)) and some prices will be auction determined. At yet higher values of $b$, the auction fraction $\lambda$ will rise. There may be a high enough value of $b<\beta$ such that the losses from price setting exceed those from auctioning even when all prices are set by auction. In such a case, no prices will be set. Varying the value of $b$ through the range 0 to $\beta$ clearly affects the slope of the tradeoff $(1-\lambda)(\beta-b)$ from two sources, directly by lowering the gap $(\beta-b)$ and indirectly by raising the auction fraction $\lambda$ and, therefore, by lowering the price setting fraction $(1-\lambda)$. Both effects tend to reduce the slope of the tradeoff making output less sensitive to prices.

At the critical value $b=\beta$, the losses (which are the same for both uniform staggering and bunching) under price setting, and under auctioning will be determined as

$$
\left.\begin{array}{l}
L_{u}^{*}=\left(\frac{9}{16}\right)^{1 / 3}(\& \beta \mu)^{2 / 3}+\sigma^{2} \\
L_{a}=\frac{x}{\beta^{2}} \sigma^{2}
\end{array}\right\}
$$

The losses now are independent of the fraction that auction and $\lambda=1$ if

$$
\frac{\gamma}{\beta^{2}} \sigma^{2}<\left(\frac{9}{16}\right)^{1 / 3}\left(\delta \beta_{\mu}\right)^{2 / 3}+\sigma^{2}
$$

and $\lambda=0$ otherwise. 
At values of $b>\beta$, set prices will be staggered but the tradeoff will have a negative (perverse) slope. The effect of higher and higher values of $b(>\beta)$ on the tradeoff slope will also be negative. That is, the slope will become increasingly negative.

Now consider the effects of alternative trend growth rates for the money supply. For a given value of $b$, the loss from price setting is minimized when the money supply growth trend, $\mu$, is equal to zero. In that case, the loss from price setting (whether bunched or staggered) is given by

$$
L_{s}^{*}=\left(1+\frac{\lambda(\beta-b)^{2}}{(\lambda b+(1-\lambda) \beta)^{2}}\right) \sigma^{2}
$$

Comparing this with equation (55) which gives the loss attaching to auctioning, it is evident that, if $\gamma>\beta^{2}$ all prices will be set and agents will be indifferent as between bunching and staggering. If $\gamma<\beta^{2}$ then all prices will be determined by auction. If $\gamma<\beta^{2}$ and all prices are determined by auction even if there is a zero money supply growth rate, then, as $\mu$ increases so the auction becomes even more attractive and nothing happens to move agents from the auction solution. If on the other hand $\gamma>\beta^{2}$, then, at a zero money supply growth rate there will be no auctions. As higher and higher values of $\mu$ are contemplated however there will come a critical value at which it will begin to pay some agents to auction. As 4 continues to rise so more and more agents would come to find auctioning the least costly solution. Eventually, $\mu$ would reach a critical value such that all agents would find it profitable to auction. Through the intermediate range of $\lambda$, the value of $\lambda$ will be a rising function of $\mu$. 
Is there anything that can be done with combination policies--with a combination of the monetary growth rate and the degree of accommodation to minimize losses from price setting and auctioneering in this economy? Evidently there is. Clearly a money supply growth trend of 0 is that which, for given b, minimizes losses from price setting. The money supply growth trend does not however have an effect upon the losses arising from auctioning. Further the value of the uncontrollable loss arising from demand noise is uninfluenced by the money supply growth rate: This noise is reduced to a minimum by setting the feedback parameter b equal to the demand elasticity B. Thus, with a zero money supply growth rate (and this of course would generalize to a growth rate equal to the growth rate of real output multiplied by the income elasticity of demand if real growth were being allowed for) and with $b$ set equal to $\beta$ the losses become

$$
\left.\begin{array}{l}
L_{s}^{*}=\sigma^{2} \\
L_{a}=\frac{y}{\beta^{2}} \sigma^{2}
\end{array}\right\}
$$

This economy will be one which displays no trend in its price level, no correlation between nonsystematic components of deviations of the price level from the expected level and deviations of output from the natural rate. Whether prices are set or determined by auction will depend on the relative magnitude of $\frac{y}{\beta^{2}}$ and, if prices are set agents will be indifferent as between whether they should be bunched or uniformly staggered.

A key feature of the "new Keynesian" model of aggregate supply is the inertia which results from overlapping price (wage) adjustments. It is apparent that there.. is no inertia in the model developed here. There is noise in the price level but that noise arises purely from auction prices and not from set prices. That being so, and because the noise process itself is free from inertia, so prices (and output) display no serial correlation. ${ }^{13}$ 
IV. CONCLUSIONS AND POSSIBLE EXTENSIONS

This paper has developed a simple model in which prices may be set or be determined by auction. It is shown the conditions under which each of these alternatives will be chosen and determined the equilibrium allocation of agents between these two methods of trading. It has also established the properties of the output-inflation tradeoff in such an economy. More crucially, it has shown that the properties of the output-inflation tradeoff are determined parameters of the money supply process and not some "exogenously given" institutional features of the economy. Indeed, the institutional features-the length of price review periods and the extent to which prices are set or auction determined--itself depends crucially on the monetary policy parameters. The model which has been used to generate these results is, of course, far from general. In some respects this is a weakness but in others a strength--it at least enables results to be obtained. The next step however, is to see how robust the results are--not in detail, but in broad terms. No doubt the detailed results will be very sensitive to the detailed assumptions made. The broad conclusion however, that market institutions depend on policy processes may well turn out to be more robust than the individual detailed results generated here. The way to establish that will be to explore the implications of modifying some of the key assumptions employed above. Some obvious extensions which suggest themselves are: first, the generalization of the money supply process to one that can cope with a randomly varying money supply growth rate embodying some form of serial correlation. Such a modification will radically alter the choice problem faced by individual price setters and will take the analysis a good deal away from the new Keynesian world of fixed contract length. It is well known that, with serially correlated disturbances, optimal policy involves setting a price not for a 
deterministically chosen period, but setting a price and choosing a pair of barriers for random demand fluctuations, the occurrence of which will trigger a new randomly timed price review. A second modification to the money supply process that would repay investigation would be the introduction of an explicit feedback rule (incorporating a time delay) rather than the contemporaneous accommodation employed here. A third extension would involve the more explicit examination of alternative theories about search behavior that presumably underlie the form of demand function employed in this paper. Such an analysis would hopefully yield greater insights into the benefits of price setting and costs of doing business at a random auction price. This would further (hopefully) lead to more convincing stories about auction costs. Finally, there is a clear need to attempt modeling of this type at a deeper level than that employed in this paper so that the firm's decision as to price setting versus auctioning as well as output rate price and optimal review period may all be derived from profit maximization subject to demand and technology constraints in an explicit way. 


\section{FOOTNOTES}

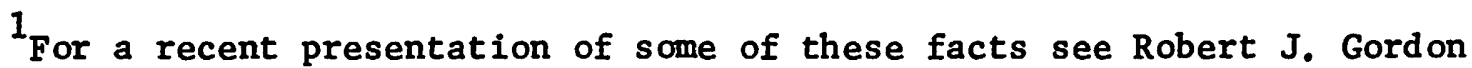
(1982).

2 See Lucas (1980), p. 703. The distinction between "market clearing" and "equilibrium" was first made clear to me by Herschel Grossman in a conversation at Brown University in 1972.

3 I do not distinguish explicitly between "households" and "firms" or between the supply of factor services and final goods and services. I find it convenient to think of the economy as producing "backscratching" services (Barro (1976), p. 5, fn. 7).

${ }^{4}$ The alternative to this would be to assume a world of monopolistic competition. This appears to be difficult to analyze.

$5^{5}$ The properties of the output-inflation tradeoff in a world of serially correlated disturbances would repay investigation. A potential basis for such an investigation which employs a random-walk demand disturbance is the important paper by Robert Barro (1972).

${ }^{6}$ The money supply growth process in (7) is purposely chosen to be of a similar form to that used by Taylor (1979). It could be modified by adding a white noise disturbance without affecting what follows. It could not, however, without radically changing the subsequent analysis, be specified as having a random trend growth rate $\mu$. Such a modification would most naturally be handled in combination with the relaxation of the white noise assumption on $v$. 
7 Ideally, the maximm problem for the producer would be specified at a deeper level so that the loss function (14) was explicitly derived from the demand and cost conditions. Such an exercise appears to be extremely untidy and unyielding of easily interpreted solutions. The loss function used may be regarded as an approximation to the true loss function and defended on grounds of tractability.

8 These two papers analyze labor supply and wages and show that, if households are risk averse and producers are risk neutral, a fixed wage set at a level such that it yields the same expected utility for households as would a random wage, will give a higher expected profit for producers. The assumption made here is analogous.

${ }^{9}$ See Taylor (1980) equation (9) and discussion on pp. 6-7. 10 John Hicks (1965, p. 77 and 1974, pp. 59-85).

${ }^{11} \mathrm{An}$ alternative 'story' that would weaken and possibly remove this condition is the introduction of auction set-up costs.

${ }^{12}$ The derivatives in (60) will be different if there is bunching from those under staggering. The signs will not, however, be different. ${ }^{13}$ It would, of course, be a simple matter to incorporate serial correlation in this model in an analogous manner to Lucas (1973). 


\section{REFERENCES}

Arrow, Kenneth, J., "Toward a Theory of Price Adjustment," in M. Abramowitz, (ed.), The Allocation of Economic Resources (Stanford, Stanford University Press, 1959).

Azariades, Costas, "Implicit Contracting and Underemployment Equilibria," Journal of Political Economy, Vol. 83, No. 6, December 1975, pp. 11831202.

Baily, Martin, N., "Wages and Employment Under Uncertain Demand," Review of Economic Studies, Vol. XLI (1), January 1974, pp. 37-50.

Barro, Robert J., "A Theory of Monopolistic Price Adjustment," Review of Economic Studies, Vo1. XXXIX (1), January 1972, pp. 17-26.

Frydman, Roman, "Towards an Understanding of Market Processes: Individual Expectations, Market Behavior and Convergence to Rational Expectations Equilibrium," manuscript, New York University, April 1981.

Gordon, Robert J., "Why U.S. Wage and Employment Behavior Differs from that in Britain and Japan," Economic Journa1, 92, March 1982, pp. 13-44.

Hicks, John, Capital and Growth, London, Oxford University Press, 1965. Hicks, John, The Crisis in Keynesian Economics, Oxford, Basil Blackwel1, 1974. Lucas, Robert E., Jr., "Expectations and the Neutrality of Money," Journal of Economic Theory, Vol. 4, April 1972, pp. 103-24.

Lucas, Robert E., Jr., "Some International Evidence on Output-Inflation Tradeoffs," American Economic Review, Vo1. 63, June 1973, pp. 326-34.

Lucas, Robert E., Jr., "An Equilibrium Model of the Business Cycle," Journal of Political Economy, Vo1. 83, December 1975, pp. 1113-44.

Lucas, Robert E., Jr., "Methods and Problems in Business Cycle Theory," Journal of Money, Credit and Banking, Vol. XII, November 1980, Pt2, pp. 696-715. 
Mussa, Michael, "The Welfare Cost of Inflation and the Role of Money as a Unit of Account," Journal of Money, Credit and Banking, Vol. IX, May 1977, pp. 276-286.

Phelps, Edmund, S., (ed.), Microfoundations of Employment and Inflation Theory,

W. W. Norton and Co., New York, 1970.

Phelps, Edmund S., "The Trouble with 'Rational Expectations' and the Problem of Inflation Stabilization," manuscript, Columbia University, October 1981. Rowlatt, Penelope, "A Micro-Model of Price Inflation," Economica, Vol. 43, No. 171, August 1976, pp. 255-66. Sargent, Thomas, J., and Neil Wallace, "'Rational' Expectations, the Optimal Monetary Instrument and the Optimal Money Supply Rule," Journal of Political Economy, Vol. 83, April 1975, pp. 241-54. Sheshinski, Eytan and Yoram Weiss, "Inflation and the Cost of Price Adjustment," Review of Economic Studies, Vol. XIIV (2), No. 137, June 1977, pP. 287-304. Taylor, John B., "Staggered Wage Setting in a Macro Model," American Economic Review, Papers and Proceedings, Vol. 69, No. 2, May 1979, pp. 108-13. Taylor, John B., "Aggregate Dynamics and Staggered Contracts," Journa1 of Political Economy, Vol. 88, No. 1, February 1980, pp. 1-23. Townsend, Robert M., "Forecasting the Forecasts of Others," manuscript, Carnegie-Mellon University, August 1980. Townsend, Robert M., "Equilibrium Theory with Disparate Expectations: Issues and Methods," manuscript, Carnegie-Mellon University, November 1981. 